\title{
PROTAGONIST
}

\section{Laparoscopic fundoplication is the treatment of choice for gastro-oesophageal reflux disease}

\section{Lundell}

Surgical treatment of gastro-oesophageal reflux disease (GORD) has previously been limited to chronic complicated reflux in patients with very longstanding severe symptoms. There is now an increasing tendency in many countries to utilise surgery in the earlier stages of the disease. ${ }^{1}$ This change in clinical practice is partly due to advances in surgical technique (laparoscopic approach) but paradoxically is also probably due to improvement in medical therapy. ${ }^{23}$ With the efficacy and availability of modern medical therapy, the focus, as well as the opportunities of therapy in GORD, have changed but also the recognition of the magnitude of the impairment in quality of life of GORD patients who are not adequately treated. ${ }^{4}$ This increased awareness may be the most pregnant cause of the suggested increase in prevalence of the disease in the adult population.

An important background factor for the significant but not eminent strategic decisions to be taken in the long term management of GORD patients is the fact that there are shortcomings and drawbacks with pharmacological maintenance therapy. GORD is a disease of a chronic nature where medical therapies are entirely targeting the control of acid reflux and not correcting the underlying motor abnormalities of the upper alimentary canal. ${ }^{5}$ Low dose proton pump inhibitor (PPI) therapy and full dose $\mathrm{H}_{2}$ receptor antagonists insufficiently interfere with food stimulated acid production and the latter also have a significant tachyphylaxis problem..$^{6-8} \mathrm{~A}$ profound and sometimes prolonged acid rebound phenomenon is perhaps a greater problem after PPI therapy in Helicobacter pylori negative subjects than previously recognised. Furthermore, in patients with severe reflux disease, twice daily dosing of PPI is often necessary. In addition, there is sometimes insufficient control of volume reflux, nocturnal symptoms, and retrosternal pain. Acid breakthrough during the night has recently been recognised and a novel more complicated medical strategy has subsequently been designed. ${ }^{9}$ Another aspect causing some concern is worsening of the inflammation of the gastric mucosa in the corpus area and in Helicobacter pylori infected subjects. This topic has been vigorously debated recently. ${ }^{11}$ An additional issue of potential concern is the controversy prevailing regarding the significance of the non-acid reflux components (bile and pancreatic juice constituents) and their probable effects on the occurrence of columnar metaplasia ${ }^{12}$ as well as their impact on the perpetuation of the metaplastic-dysplastic processes leading to the rapidly increasing incidence of adenocarcinoma of the oesophagus. ${ }^{13}{ }^{14}$ These many concerns already have an important impact on the attitudes towards complete control of reflux and will continue to do so in the future. Taken together, there seems to be a growing demand for complete and durable control of reflux based on the principle of reconstruction of the physiology of the gastro-oesophageal junction, which seems to be a reachable goal when a proper antireflux operation is performed.

A number of patient groups can be identified who are particularly suited to a laparoscopic antireflux operation. This decision is based mostly on the patient's own preferences after a comprehensive and prolonged discussion with an experienced surgeon. The first group is those with chronic uncomplicated reflux disease which partly or totally responds to modern PPI therapy and requires continued medication to control the disease. Antireflux operations were previously indicated in cases where medical treatment could not prevent the disease from having a significant negative impact on the patient's quality of life. This indication is still valid but modern therapy is so effective that only a minority of patients do not obtain substantial or complete relief of their symptoms. The problem of rapid and consistent relapse on cessation of therapy has been referred to, but perhaps more importantly is that many patients with chronic reflux do not want to be reliant on a form of medication that is yet to establish its safety over many years of continuous use ( $>10$ years). Hence an important question we should ask is, are patients who do not respond adequately to PPI therapy suitable candidates for antireflux surgery? In a recent randomised clinical trial comparing open antireflux surgery with omeprazole, approximately $10 \%$ of patients were not initially controlled on $40 \mathrm{mg}$ omeprazole daily. ${ }^{15}$ These patients were then, according to the protocol, offered antireflux surgery and did very well compared with the main group of patients randomised to respective therapies. The important message therefore must be that remaining symptoms of reflux and only a partial response to PPI therapy should not be considered unfavourable factors for the subsequent postoperative course after antireflux surgery.

\section{COMPLICATED REFLUX DISEASE}

Secondly, there is a group of patients with complicated reflux disease, represented by peptic strictures, the treatment of which has been greatly improved by the introduction of PPI. ${ }^{16}$ However, dilatable strictures in a young healthy patient is still an indication for fundoplication 
and dilatation. Furthermore, gastro-oesophageal regurgitation associated with aspiration of gastric juice into the pharynx and into the respiratory tree can cause laryngitis, recurrent pneumonia, bronchitis, and asthma. Respiratory complications due to reflux are firmly established indications for antireflux surgery although scientific evidence for the true benefit of antireflux surgery in an unselected group of reflux patients with alleged respiratory complications has still to be found. ${ }^{17-19}$ Indicated in the complicated reflux disease group is Barrett's oesophagus (columnar lined oesophagus (CLO)). There is no consensus as to whether CLO remains an absolute indication for antireflux surgery. Evidence suggests that continued reflux may be deleterious for the dysplastic process in the oesophageal mucosa and in fact the results of a randomised trial presented some years ago suggested that antireflux surgery had advantages over medical therapy. ${ }^{20}$ However, a comprehensive comparison between antireflux surgery and modern updated PPI therapy has not been carried out in CLO patients. Recent circumstantial information would indicate that antireflux surgery has the potential to reverse metaplastic lesions in the cardiac region of reflux patients but continued follow up and more extensive clinical research are needed to allow firm conclusions on this delicate issue. ${ }^{21}{ }^{22}$ At present, it can be concluded that antireflux surgery should aim for reflux and symptom control in patients with Barrett's oesophagus rather than primarily to prevent progression of CLO and/or induce regression. In this context however it is interesting to note that adenocarcinoma of the oesophagus has been observed only rarely $\geqslant 5$ years after a functioning antireflux procedure ${ }^{23}$ in CLO patients. In addition, recent clinical research has found that antireflux operations prevent the occurrence of intestinal metaplasia in columnar lined oesophagi. ${ }^{24}$

\section{RECONSTRUCTION OF THE PHYSIOLOGY OF THE GASTRO-OESOPHAGEAL JUNCTION BY OPERATION}

It is likely that all fundoplications being either total, partial anterior or posterior work in a similar way. This may be by both mechanical and physiological processes as these wraps are effective not only when placed in the chest in vivo but also when tested in animal viscera ex vivo. ${ }^{25}$ The principles of fundoplication operations are to mobilise the lower part of the oesophagus and to wrap the fundus of the stomach either partially or totally around the oesophagus. When the oesophageal hiatus is enlarged, it is narrowed by sutures to prevent para-oesophageal herniation and also to prevent the wrap from being pulled up into the chest. Antireflux procedures focus on three main components. Firstly, there is the anatomical repositioning of the lower oesophageal sphincter into the abdominal positive pressure environment with reduction of the hiatal hernia sack by dissection, mobilisation, and positioning of the crural sutures. This anatomical restoration per se may also have the potential to prevent reflux by reducing the hiatal hernia and by improving oesophageal clearance and crural function. ${ }^{26}$ Secondly, it has been suggested that peristaltic amplitude and other oesophageal body motor functions may improve after antireflux operations. However, it is not known if these observations can be explained by secondary compensatory mechanisms operational due to a subclinical outflow obstruction in the gastrooesophageal junction caused, for example, by total fundoplication. ${ }^{27}$ Thirdly, the resting pressure of the lower oesophageal sphincter (LOS) and lengthening of the abdominal portion of the high pressure zone are important consequences of these operations. By continuously assessing LOS tone over a longer period of time, it has been shown that the pressure was considerably higher after total than after a partial posterior fundoplication. ${ }^{28}$ It should be noted that in the latter group the pressure level of the LOS region was very close to that seen in normal healthy controls. It should also be considered that total fundoplication may even over correct the mechanical deficiencies in the gastro-oesophageal junction with the risk of eliciting a super competent cardia. After a successful antireflux operation, LOS pressure never reaches a level at which free reflux is considered to occur. ${ }^{29-31}$ Furthermore, the number of transient LOS relaxations and the proportion of those associated with reflux are substantially reduced by an antireflux operation. After these operations, gas insufflation into the stomach or meal ingestion seldom elicit transient LOS relaxations which contrasts with the situation in unoperated GORD patients when these stimuli may trigger repeated relaxation of the LOS accompanied by reflux..$^{28}{ }^{32}$ Venting of air from the stomach may be a problem after some antireflux operations but it is easier after partial fundoplication than a total fundic wrap, as indicated by the occurrence of common cavities during manometry after gas insufflation into the stomach.

To complete the picture of restorative functions, it should be noted that delayed gastric emptying may be a contributory pathogenetic factor in up to $40 \%$ of GORD cases. ${ }^{33}$ Postfundoplication studies have consistently demonstrated accelerated gastric emptying after these operations. This is probably caused by a high gastric tone postprandially in the postoperative situation which accelerates the transfer of chyme to the distal part of the stomach thus facilitating emptying. ${ }^{356}$

Taken together, I conclude that antireflux procedures seem to significantly interfere with, and at least partly correct, important pathogenetic deficiencies in chronic GORD patients.

\section{HOW TO REDUCE THE POTENTIAL DISADVANTAGES WITH ANTIREFLUX PROCEDURES?}

There is a definite learning curve for surgeons in performing a laparoscopic fundoplication which strongly endorses the idea of centralising these procedures to high volume high quality centres and also the supervision of the surgical practice by an experienced surgeon. ${ }^{37}$ These specialised centres, with particular interest and understanding of the disease processes, also have the available technology to assess patients both before and eventually after their antireflux

Debate 
Debate

procedure.$^{38}{ }^{39}$ It is particularly important to offer similar services when problems or failures emerge.

The most frequent postfundoplication symptoms are dysphagia, inability to belch-vomit, postprandial fullness, bloating and pain, and socially embarrassing rectal flatus. The frequency with which these postfundoplication symptoms have been reported varies considerably between series. ${ }^{40}{ }^{41}$ Dysphagia is frequently reported during the early postoperative period but seems to diminish with the passage of time, as may other postfundoplication symptoms. A recent randomised clinical trial suggest that laparoscopic total fundoplications are associated with more obstructive complaints in the early postoperative period than open procedures. ${ }^{42}$ Other similar trials have not been able to confirm these potential hazards of laparoscopic operations. ${ }^{43-45}$ However, as effective treatment for established severe postfundoplication symptoms is lacking, prevention is mandatory. There is a widespread consensus among experienced surgeons that if a complete wrap is performed it has to be both floppy and short. A large randomised trial has reported that posterior partial fundoplication is associated with less troublesome complaints of gas bloat-rectal flatus ${ }^{46}$ Furthermore, laparoscopic anterior partial fundoplication has recently been reported to have similar advantages. ${ }^{47}$

Failure of fundoplication to control reflux occurs in a minority of patients. There are reports of a considerably high failure rate and it is important to emphasise that essentially all failures occur early in the postoperative period, indicating the importance of adhering to technical details and expertise..$^{4-52}$ There are no data available to suggest that the failure rate is higher after laparoscopic fundoplication than traditionally seen after open operations..$^{53}$ Success rates after redo surgery for failed primary operations are generally lower than after index operations. This should be taken into consideration, together with the fact that postoperative morbidity and mortality is many times higher. These data provide a strong case for referring these patients to specialised tertiary referral centres for assessment and careful investigations but also to ensure adequate surgical expertise to minimise the risk and optimise subsequent functional outcome.

\section{THE US VETERAN MESSAGE}

Unfortunately, very few randomised controlled clinical trials have been carried out comparing antireflux surgery with modern medical therapy. So far only one study has performed a head-tohead comparison between omeprazole and antireflux surgery in 310 oesophagitis patients ${ }^{54}$ in which a slight advantage of the operative treatment was observed after a minimum follow up period of five years. In the USA, a similar trial was initiated many years ago in severe reflux patients recruited from VA hospitals at a time when medical therapy was quite different from the present level of efficacy. The two year follow up data showed effects strongly in favour of surgical therapy. ${ }^{55}$ Using a unique methodology, 38 of the initial 82 operated patients were traced 10 years after operation and the results of this long term follow up have recently been published. ${ }^{56}$ There are a number of very important issues raised by this study. One is the high frequency of antisecretory drugs taken by operated patients, allegedly to control recurrent reflux symptoms. In this context it is important to realise that it is not sufficient to just record the fact that patients may take antisecretory therapy after similar operations as the reasons vary considerably, as we found in our randomised controlled clinical trial ${ }^{54}$ and others have found when patients have been followed up many years after laparoscopic fundoplication. ${ }^{57}$

Secondly, Spechler and colleagues ${ }^{56}$ found that operated patients had a survival curve that was significantly inferior to that of medically treated patients. This enhanced mortality after an antireflux operation was mainly due to cardiovascular events but did not stop the authors from drawing conclusions on the attitude towards the indication for antireflux surgery. In our Nordic GORD trial,,$^{54}$ after a minimum of seven years of follow up, no survival difference between operated and non-operated patients was found.

Thirdly, there was no significant difference in the number of adenocarcinomas when the two study groups were compared (one in the antireflux surgery group and four in the medically treated group). The number of events was to small to allow meaningful comparisons but what is important is to assess the function of the antireflux procedure in patients who develop adenocarcinoma after antireflux surgery (see above).

\section{REFERENCES}

1 Watson DI, Foreman D, Devitt PG, et al. Preoperative endoscopic grading of oesopahgitis vs. outcome after laparoscopic Nissen fundoplication. Am J Gastroenterol 1997; 92:222-5

2 Klinkenberg-Knol E, Festen $\mathrm{H}$, Jansen J, et al. Long term treatment with omeprazole for refractory reflux esophagitis: efficacy and saftey. Ann Intern Med 1994;121:161-7.

3 Bardhan KD. The role of the proton pump inhibitors in the treatment of gastroesophageal reflux disease. Aliment Pharmacol Ther 1995;9(suppl I): 15-25.

4 Blomqvist A, Dalenbäck J, Lönroth $\mathrm{H}$, et al. Quality of life assessment after laparoscopic and open fundoplications: Results of prospective clinical studies. Scand J Gastroenterol 1996:31:1052-8.

5 Lundell L. Acid suppression in the long term treatment of peptic strictures in Barrett's oesophagus. Digestion 1992;51(suppl 1):49-58

6 Scarpignato C, Galmiche JP. The role of $\mathrm{H}_{2}$ receptor antagonist in the area of proton pump inhibitors. In: Lundell L, ed. Guidlines for management for symptomatic gastroesophageal reflux disease. London: Science Press, 1998:55-66

7 El-Omar E, Benerjee S, Wirz A, et al. Marked rebound acid hypersecretion after treatment with ranitidine. $\mathrm{Am} \mathrm{J}$ Gastroenterol 1996;91:355-9.

8 Gillen D, Wirz AA, Ardill JE, et al. Rebound hypersecretion after omeprazole and its relation to on-treatment acid suppression and Helicobacter pylori status. Gastroenterology 1999:116:239-47.

9 Leite LP, Johnston BT, Just RJ, et al. Persistent acid secretion during omeprazole therapy: A study of gastric acid profiles in patients demonstrating failure of omeprazole therapy. Am J Gastroenterol 1996:91:1527-51.

10 Keupers EJ, Lundell L, Klinkenberg-Knol E, et al. Athrophic gastritis in Heilicobacter pylori infection in patients with reflux esophagitis treated with omeprazole or fundoplication. N Engl J Med 1996;334:1018-22.

11 Lundell L, Miettinen P, Myrvld HE, et al. Lack of effect of acid suppression therapy and gastric atrophy. Results from a randomised clinical study. Gastroenterology 1999;117:319-26

12 Attwood SE, Smyrk TC, DeMeester TR, et al. Duodenoesophageal reflux and the development of adenocarcinoma in rats. Surgery 1992;111:503-10. 
13 Pera AM, Cameron AJ, Trastec VF. Increasing incidence in adenocarcinoma of the esopahgus and esophagogastric junction. Gastroenterology 1993;104:510-13

14 Lagergren J, Bergström R, Lindgren A, et al. Symptomatic gastroesophageal reflux as a risk factor for esopahgeal adenocarcinoma. N Engl J Med 1999;340:825-31

15 Lundell L, Dalenbäck J, Hattlebakk J, et al. Nordic GORD-study Group. Outcome of open antireflux surgery as assessment in a Nordic multicenter, prospective clinical trial. Eur J Surg 1998;164:751-7.

16 Marks RD, Richter JE, Rizzo J et al. Omeprazole versus $\mathrm{H}_{2}$-receptor antagonists in treating patents with peptic stricture and oesophagitis. Gastroenterology 1994;106:907-15.

17 DeMeester TR, Bonavina L, Lascone C, et al. Chronic respiratory symptoms and occult gastroesophageal reflux: a prospective clinical trial and results of surgical therapy. Ann Surg 1990;211:337-45.

18 Ruth M, Bake B, Sandberg N, et al. Pulmonary function in gastroesophageal reflux disease. Effects of reflux controlled by fundoplication disease of the esophagus. Dis Esophagus 1994;7:268-75.

19 Ford GA Olover PS Prior JS et al Omeprazole in the treatment of asthma dippers with nocturnal symptoms and gastroesophageal reflux: a placebo controlled cross over study. Post Grad Med J 1994;70:350-4

20 Ortiz A, Martinez LF, Parrilla P, et al. Conservative treatment vs antireflux surgery in Barrett's oesophagus: long-term results of a prospective study. Br J Surg 1996;83:274-8

21 Csendes A, Braghetto I, Burdiles P, et al. Long-term results of classic antireflux surgery in 152 patients with Barrett's esophagus: Clinical radiologic, endoscopic, manometric and acid reflux test analysis before and late after operation. Surgery 1998;123:645-57.

22 Öberg S, Peters JH, DeMeester TR, et al. Inflammation and specialized intestinal metaplasia of cardiac mucosa is a manifestation of gastroesophageal reflux disease. Ann Surg 1997;226:522-32.

23 Lundell L. Prevention of cancer by control of reflux. In: Barrett's oesophagus. Tilanus and Attwood, eds. Kluwer Academic Publisher, 2000.

24 Öberg S, Johansson J, Wenner J, et al. Metaplastic columnar mucosa in the cervical esophagus following esophagotomy. Ann Surg 2002;235:338-45.

25 Watson DI, Mathew G, Pike GK, et al. Comparison of anterior, posterior and total fundoplication using a viscera model. Dis Esophagus 1997:10:110-14.

26 Kahrilas PJ, Lin S, Chen J. The effect of hiatus herina on gastro-oesophageal junction pressure. Gut 1999;44:476-82

27 Rydberg L, Ruth M, Lundell L. Does oesophageal motor function improve with time after successful antireflux surgery? Results of a prospective, randomised clinical study. Gut 1997;41:82-6.

28 Rydberg L, Ruth M, Lundell L. Mechanism of action of antireflux procedures. Br J Surg 1999;86:405-10.

29 Holloway RH, Kocyan P, Dent J. Provocation of transient lower esophageal reflux by meals in patients with symptomatic gastroesophageal reflux. Dig Dis $\mathrm{Sci}$ 1991;36:1034-9.

30 Schoeman MN, Tippett MD, Akkermans LM, et al. Mechanisms of gastroesophageal reflux in ambulant healthy human subjects. Gastroenterology 1995; 108:83-91.

31 Banciewicz J, Mughai M, Marples M. The lower esophageal sphincter after floppy Nissen fundoplication. Br J Surg 1987;74:162.

32 Johnsson F, Holloway RH, Ireland AC, et al. Effect of fundoplication on transient lower oesophageal sphincter relaxation and gas reflux. Br J Surg 1997;84:686-9.

33 Mc Callum RW, Berkowitz DM, Lerner E. Gastric emptying in patients with gastrooesophageal reflux. Gastroenterology 1981;80:285-91.

34 Velasco N, Hill LD, Ganna RM, et al. Gastric emptying and gastrooesophageal reflux. Am Surg 1982;144:58-62.
35 Maddern GJ, Jaimeson GG. Fundoplication enhances gastric emptying. Ann Surg 1985:301:296-9

36 Vu MK, Straathof JWA, Schaar PJ, et al. Motor and sensory function of the proximal stomach in reflux disease Gastroenterol 1999:94:1481-9.

37 Watson DI, Baigrie R, Jaimeson GG. A learning curve for laparoscopic fundoplication. Definable, avoidable, or a waste of time? Ann Surg 1996;224:198-203.

38 Viliakka $M$, Luostarinen $M$, Isolauri J. Incidence of antireflux surgery in Finland 1988-1993. The influence of proton pump inhibitors and laparoscopic technique. Scand J Gastroenterol 1997;2:415-18.

39 Loustarinen MES, Isolauri JO. Surgical experience improve the long-term results of Nissen fundoplication. Scand J Gastroenterol 1999;34:117-20.

40 Peridikis G, Hinder RA, Lund R, et al. Laparoscopic Nissen fundoplicatio: Where do we stand? Surg Laparosc Endosc 1997:7:17-21.

41 Watson DI, Jamieson GG. Antireflux surgery in the laparoscopic area. Br J Surg 1998;85: 1 173-84.

42 Bais JE, Bartelsman JFWM, Bonjer HJ, et al. Laparoscopic or conventional Nissen fundoplication for gastro-oesophageal reflux disease: randomised clinical trial. Lancet 2000;355:170-4.

43 Laine S, Rantala A, Gullichsen R, et al. Laparoscopic vs conventional Nissen fundoplication. A prospective randomized study. Surg Endosc 1997;1 1:441-4.

44 Watson DI Gourlay R, Globe J, et al. Prospective randomised trial of laparoscopic (LNF) versus open (ONF) Nissen fundoplication. Gut 1994;35(suppl 2):S15 (abstract W58)

45 Nilsson G, Larsson S, Johnsson F. Randomised clinical trial of laparoscopic versus open fundoplication: blind evaluation of recovery and discharge period. Br J Surg 2000;87:873-8.

46 Lundell $L$, Abrahamsson $H$, Ruth $M$, et al. Long-term results of a prospective randomised comparison of total fundic wrap (Nissen-Rossetti) or semifundoplication (Toupet) for gastro-oesophageal reflux. Br J Surg 1996:83:830-5.

47 Watson DI, Jamieson GG, Pike GK, et al. Prospective randomized doulbele-blind trial between laparoscopic Nissen fundoplication and anterior partial fundoplication. Br J Surg 1999:86: 123-30.

48 Rieger NA, Jamieson GG, Britten-Jones R. Re-operation after failed antireflux surgery. Br J Surg 1994;81:1159-61.

49 Deschamps C, Trastec VF, Allen MS, et al. Long-term results after re-operation for failed antireflux procedures. $J$ Thorac Cardiovasc Surg 1997; 1 13:545-51.

50 Stein HJ, Feussner H, Siewert JR. Failure of antireflux surgery, causes and management strategies. Am J Surg 1996;171:36-40.

51 Luostarinen ME, Isolauri JO, Koskinen $M O$, et al. Re-fundoplication for recurrent gastroesophageal reflux. World J Surg 1993; 17:587-94.

52 Watson DI, Jamieson PA, Game PA, et al. Laparoscopic reoperation following failed antireflux surgery. $\mathrm{Br} J$ Surg 1999:86:98-101.

53 Bammer T, Hinder RA, Klaus A, et al. Five- to eight-year outcome at the first laparoscopic Nissen fundoplicatio. J Gastrointest Surg 2001;5:42-8.

54 Lundell L, Miettinen P, Myrvold HE, et al. Continued (5-year) follow-up of a randomised clinical study comparing antireflux surgery and omeprazole in gastroesophageal reflux disease. J Am Coll Surg 2001;192:172-9.

55 Spechler SJ. Comparison of medical and surgical therapy for complicated gastroesophageal reflux disease in veterans. N Engl J Med 1992;326:786-92.

56 Spechler SJ, Lee E, Ahnen D, et al. Long-term outcome of medical and surgical therapies for gastroesophageal reflux disease. JAMA 2001;285:2331-8.

57 Lord RV, Kaminski A, Bowrey DJ, et al. Absence of gastroesophageal reflux disease in a majority of patients taking acid suppression medications after Nissen fundoplication. Gastroenterology 2001;120/suppl 1):A44 


\section{Debote Arracows \\ Laparoscopic fundoplication is the treatment of choice for gastro-oesophageal reflux disease J P Galmiche, F Zerbib}

\begin{abstract}
Although the technical principles of surgical repair remain the same in laparoscopic practice as in the classical open procedure, the increasing enthusiasm of patients and many physicians for this so-called "mini invasive" surgery has led to its greater use and wider indications for surgery in gastro-oesophageal reflux disease (GORD). The notion behind this proposed change in current practice is that antireflux surgery (ARS) is more "cost effective" than medical therapy and possibly safer with regard to the long term effects of acid suppression and occurrence of adenocarcinoma of the oesophagus in patients with severe chronic GORD. Our position challenges this view, which in our opinion is not supported by scientific evidence and data in the recent literature. If it is assumed that modern drug therapy and ARS are both effective in the treatment of GORD, a comparison between them should concentrate on several end points that have been recognised as major goals of antireflux therapy. Hence in addition to healing of oesophagitis, emphasis now needs to be given to complete symptom relief, return to a normal quality of life, and long term control of the disease (that is, prevention of recurrences and complications). Tolerance, safety, and costs are also important issues.
\end{abstract}

\section{EFFICACY OF ARS VERSUS MEDICAL THERAPY}

Comparison is limited by lack of randomised trials between laparoscopic surgery and modern drug therapy (that is, proton pump inhibitors (PPIs)). Although Spechler ${ }^{1}$ first reported that open ARS was significantly better than medical therapy after two or three years of follow up, the comparison involved drugs which are no longer considered as optimal therapy for GORD. Interestingly, the same author recently reassessed the long term outcome of these cohorts of medically and surgically treated patients after a median follow up of approximately 10 years. ${ }^{2}$ Oesophagitis grade, quality of life scores, satisfaction with antireflux therapy, and frequency of GORD related complications did not differ significantly between the two groups. Recently, Lundell et al compared the results of open ARS and omeprazole after three ${ }^{3}$ and five years ${ }^{4}$ of follow up in a large multicentre prospective randomised study. Results were similar when patients in the omeprazole group were allowed to adjust for the PPI dose according to individual needs. There was no evidence of any general superiority of open ARS over long term drug treatment and there was no reason to suspect that the laparoscopic approach may be more effective than the open one. Indeed, even after successful laparoscopic ARS, quality of life does not return to normal. ${ }^{5}$ Finally, oesophageal dysmotility, if initially present, is not corrected by ARS but may eventually complicate it. ${ }^{6}$

However, one could argue that the superiority of ARS may be limited to a selected part of the GORD spectrum. In fact, there are no convincing data for the efficacy of ARS in treating patients with oesophagitis refractory to PPIs. With optimised dose and dosing frequency regimens, even severe oesophagitis is healed in more than $90 \%$ of cases after eight weeks, and this healing rate may increase with continuation of therapy. Therefore, PPI refractoriness is a rare indication for ARS. On the contrary, the more generally accepted view is that the best indication for surgery is a patient who actually responds to PPI but wishes to discontinue the medication. However, recent data do not confirm this notion because the majority of patients $(62 \%)$ continued to take antireflux medications regularly after surgery. ${ }^{2}$ The reason for this continued intake of drugs after ARS is not completely clear. Deterioration of results reported 10-20 years after surgery is usually due to disruption of the fundic wrap ${ }^{7}$ although drug consumption may not necessarily reflect therapeutic failure.

Recent studies, especially those performed in a primary care setting, have shown that up to $70 \%$ of patients with frequent heartburn do not have mucosal breaks at endoscopy (non-erosive reflux disease (NERD)). ${ }^{8}$ While randomised studies have now demonstrated the efficacy of PPIs on symptoms, quality of life, and maintenance in remission, there are no controlled or even large prospective studies of ARS in these NERD patients. Data from PPI trials indicate that these patients do not have a mild disease but frequently respond less well to acid suppression. ${ }^{9}$ For some, the role of other pathogenic factors, such as enhanced sensitivity and/or permeability of the oesophageal mucosa, may be of crucial importance. The frequent association of dyspepsia and GORD symptoms in these patients ${ }^{5}$ may also be detrimental to ARS results. Therefore, extreme caution must be exercised before extending indications for laparoscopic surgery to this group of patients.

Are GORD complications such as strictures or bleeding ulcers an indication for ARS? Although it is difficult to answer this question due to a lack of comparative studies (and the difficulty of conducting them), it is apparent that most of these complications occur in elderly patients who are poor candidates for surgery because of their general status or associated illnesses. In contrast, 
when strictures are present and symptomatic, maintenance therapy with a PPI regimen has been shown to be very effective after initial endoscopic dilatation.

Extraoesophageal manifestations of GORD, such as asthma, chronic cough, non-cardiac chest pain, and ear, nose, and throat symptoms, represent a difficult situation from both diagnostic and therapeutic standpoints. Several uncontrolled observations have suggested that open or laparoscopic ARS may reduce or even abolish atypical symptoms. ${ }^{10}{ }^{11}$ However, the same magnitude of improvement has been reported with omeprazole. ${ }^{12}$ For example, a recent uncontrolled trial evaluating titrated omeprazole treatment found that $73 \%$ of non-allergic asthmatics with symptomatic GORD and abnormal acid exposure had a clinical response. ${ }^{13}$ Finally, two placebo controlled trials showed that omeprazole was effective in patients with non-cardiac chest pain ${ }^{14} 15$ whereas only uncontrolled observations had suggested the efficacy of ARS. ${ }^{16}$ On the whole, the efficacy of both medical and surgical treatments in patients with extraoesophageal manifestations seems less impressive than in those with typical symptoms.

In summary, the available literature does not allow clear identification of a subset of patients for whom ARS may be more effective than PPI therapy. Moreover, the results of surgery are more difficult to evaluate due to the heterogeneity of techniques, the level of experience of surgeons, and the fact that evaluation criteria and study designs were less rigorously defined in surgical studies than in trials involving PPIs.

\section{SIDE EFFECTS AND LONG TERM SAFETY OF ARS VERSUS MEDICAL THERAPY}

GORD is not usually a life threatening condition..$^{10}$ Although there are now convincing data for the safety and tolerance of PPI strategies over a 10 year period, ${ }^{17} 18$ this is not the case for ARS. Postoperative mortality for ARS ranges from $0.1 \%$ to $0.8 \%$ in cohort studies and may even be slightly higher in less experienced centres. Postoperative morbidity is also quite prevalent, with the frequency of persisting dysphagia ranging between $1 \%$ and $8 \%$. Laparoscopic ARS cannot be considered safer than open ARS as a recent randomised study ${ }^{19}$ concluded that this approach is more frequently complicated by persistent postoperative dysphagia than open fundoplication. The learning curve to achieve a sufficient level of expertise in laparoscopic ARS is an important limitation, as the rate of complications continues to decline even after 100 procedures. ${ }^{20}$ The fact that morbidity after ARS is frequently underestimated may largely account for the poorer outcome after laparoscopic fundoplication in community practice than in controlled studies, as illustrated by a recent report showing only $57 \%$ complete satisfaction after surgery in a US population. ${ }^{21}$ Finally, when all safety issues are considered, the balance is clearly in favour of medical treatment. This advantage could become even greater in the future if intermittent or on-demand PPI strategies are more frequently applied to patients with NERD.

\section{RISK OF MALIGNANCIES DURING LONG} TERM TREATMENT OF GORD

The fear of patients and physicians concerning cancer development in relation to GORD itself (risk of oesophageal adenocarcinoma) or GORD therapy (risk of gastric carcinoma) is difficult to evaluate retrospectively but has probably influenced the choice between PPIs and ARS in many instances. Some experimental data, such as better control of oesophageal biliary reflux with surgery than with PPI, are favourable to ARS, although their clinical relevance is far from being fully established. The situation is also difficult because of the complexity of the relationships between GORD and Helicobacter pylori infection..$^{22}$ Although there is strong epidemiological evidence of an increased risk of adenocarcinoma of the oesophagus in patients with chronic heartburn, no definite proof exists indicating that ARS is more effective than medical therapy in preventing this rare complication. ${ }^{2}$ On the other hand, the potential risk of gastric carcinoma is more linked to Helicobacter pylori infection than to PPI therapy although these drugs may slightly increase the risk of corpus gastric atrophy. In summary, the risk of cancer during long term GORD management seems to be very low and should not influence the choice between drug therapy and ARS.

\section{MEDICOECONOMIC ASPECTS}

One argument frequently advanced in favour of ARS in young healthy patients is the reduction in therapeutic cost compared with a lifetime schedule of PPI therapy. ${ }^{23}$ Although it is difficult to extrapolate to lifetime expectancy, mathematical models as well as randomised studies do not support this assumption. For instance, Heudebert and colleagues ${ }^{24}$ found that laparoscopic ARS in severe oesophagitis may only become more cost effective than PPIs after 10 years. Moreover, the model used was extremely sensitive to the cost of complications after surgery and may even have overestimated the cost of PPIs, given the increased prescription of generic drugs. Finally, the recent results of a large prospective randomised trial of open ARS versus omeprazole conducted in Scandinavia ${ }^{25}$ indicated that drug therapy is less expensive than surgery, although cost variations in different countries are likely to be substantial, depending on healthcare systems.

\section{CONCLUSION}

Although ARS is an effective approach for long term control of GORD, its superiority over modern medical therapy is not established. Conversely, PPI therapy is efficient, safe, and cost effective in the long term (that is, at least 10 years). In view of the rapid improvement in our understanding of the pathogenesis of GORD and the potential for the development of new drugs to supplement our current medical armamentarium, it seems wise to limit indications for ARS to the following conditions: (a) refractoriness (or intolerance) to PPIs after optimising dose and dosing frequency, (b) unwillingness to continue drug therapy in a young patient fully informed about the hazards and complications of surgery, and (c) need for frequent dilatations despite adequate PPI therapy in a patient with a narrow oesophageal stricture. In patients with atypical manifestations, ARS

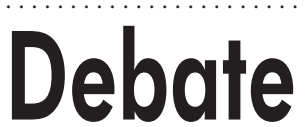




\section{Debate}

\section{Key points}

- Laparoscopic antireflux surgery is not more cost effective than PPI therapy in the long term (that is, at least 10 years).

- Postoperative morbidity after laparoscopic fundoplication is important.

- Results of laparoscopic antireflux surgery are highly surgeon dependent and probably less satisfactory in community practice than in expert centres.

- There is no evidence that laparoscopic fundoplication prevents oesophageal adenocarcinoma in GORD.

should not be proposed before the contribution of GORD to symptoms has been established and a full trial of optimised PPI has failed. The debate is now further complicated by the rapid development of endoscopic therapy of GORD ${ }^{26}$ which may represent another non-surgical option in the future.

\section{REFERENCES}

1 Spechler SJ. Comparison of medical and surgical therapy for complicated gastroesophageal reflux disease in veterans. The Department of Veterans Affairs Gastroesophageal Reflux Disease Study Group. N Engl J Med 1992;326:786-92.

2 Spechler SJ, Lee E, Ahnen D, et al. Long-term outcome of medical and surgical therapies for gastroesophageal reflux disease: follow-up of a randomized controlled trial. JAMA 2001;285:2331-8.

3 Lundell L, Miettinen P, Myrvold HE, et al. Long-term management of gastro-oesophageal reflux disease with omeprazole or open antireflux surgery: results of a prospective, randomized clinical trial. The Nordic GORD Study Group. Eur J Gastroenterol Hepatol 2000;12:879-87.

4 Lundell L, Miettinen P, Myrvold HE, et al. Continued (5-year) followup of a randomized clinical study comparing antireflux surgery and omeprazole in gastroesophageal reflux disease. J Am Coll Surg 2001;192:172-9

5 Slim K, Bousquet J, Kwiatkowski F, et al. Quality of life before and after laparoscopic fundoplication. Am J Surg 2000;180:41-5

6 Fibbe C, Layer P, Keller J, et al. Esophageal motility in reflux disease before and after fundoplication: a prospective, randomized, clinical, and manometric study. Gastroenterology 2001;121:5-14.

7 Luostarinen M, Isolauri J, Laitinen J, et al. Fate of Nissen fundoplication after 20 years. A clinical, endoscopical, and functional analysis. Gut 1993;34:1015-20.

8 Galmiche JP, Barthelemy P, Hamelin B. Treating the symptoms of gastro-oesophageal reflux disease: double-blind comparison of omeprazole and cisapride. Aliment Pharmacol Ther 1997;11:765-73.

9 Carlsson R, Dent J, Watts R, et al. Gastro-oesophageal reflux disease in primary care: an international study of different treatment strategies with omeprazole. International GORD Study Group. Eur J Gastroenterol Hepatol 1998;10:119-24.

10 Kahrilas PJ. Management of GERD: medical versus surgical. Semin Gastrointest Dis 2001;12:3-15.

11 So JB, Zeitels SM, Rattner DW. Outcomes of atypical symptoms attributed to gastroesophageal reflux treated by laparoscopic fundoplication. Surgery

$$
\text { 1998;124:28-32. }
$$

12 Kamel PL, Hanson D, Kahrilas PJ. Omeprazole for the treatment of posterior laryngitis. Am J Med 1994;96:321-6.

13 Harding SM, Richter JE, Guzzo MR, et al. Asthma and gastroesophageal reflux: acid suppressive therapy improves asthma outcome. Am J Med 1996;100:395405.

14 Achem SR, Kolts BE, MacMath T, et al. Effects of omeprazole versus placebo in treatment of noncardiac chest pain and gastroesophageal reflux. Dig Dis Sci 1997;42:2138-45

15 Fass R, Fennerty MB, Ofman JJ, et al. The clinical and economic value of a short course of omeprazole in patients with noncardiac chest pain. Gastroenterology 1998;115:42-9.

16 Tibbling L, Gibellino F. Remission of angina pectoris and dyspnea by fundoplication in gastro-oesophageal reflux disease. Ann Med 1992;24:457-9.

17 Armstrong D. Long-term safety and efficacy of omeprazole in gastro-oesophageal reflux disease. Lance 2000;356:610-12

18 Klinkenberg-Knol EC, Nelis F, Dent J, et al. Long-term omeprazole treatment in resistant gastroesophageal reflux disease: efficacy, safety, and influence on gastric mucosa. Gastroenterology 2000;1 18:661-9.

19 Bais JE, Bartelsman JF, Bonjer HJ, et al. Laparoscopic or conventional Nissen fundoplication for gastro-oesophageal reflux disease: randomised clinical trial. The Netherlands Antireflux Surgery Study Group. Lancet 2000;355: 170-4

20 Soot SJ, Eshraghi N, Farahmand M, et al. Transition from open to laparoscopic fundoplication: the learning curve. Arch Surg 1999;134:278-81.

21 Vakil N, Treml S, Shaw M, et al. The outcome of laparoscopic fundoplication for reflux disease in community practice in the USA. Gastroenterology 2001;120:A16.

22 O'Connor HJ, O'Morain CA. Helicobacter pylori and gastroesophageal reflux disease: to treat or not to treat? Scand J Gastroenterol 2001;36:677-82.

23 Viliakka M, Nevalainen J, Isolauri J. Lifetime costs of surgical versus medical treatment of severe gastro-oesophageal reflux disease in Finland. Scand J Gastroenterol 1997;32:766-72.

24 Heudebert GR, Marks R, Wilcox CM, et al. Choice of long-term strategy for the management of patients with severe esophagitis: a cost-utility analysis.
Gastroenterology 1997;1 12:1078-86.

25 Myrvold HE, Lundell L, Miettinen P, et al. The cost of long term therapy for gastro-oesophageal reflux disease: a randomised trial comparing omeprazole and open antireflux surgery. Gut 2001:49:488-94.

26 Galmiche JP, Barouk J. Endoscopic treatment of gastroesophageal reflux disease: fact or fancy? Curr Gastroenterol Rep 2002;4:177-8 